Supplementary Information

\title{
Bicontinuous Fluid Structure with Low Cohesive Energy- Molecular Basis for Exceptionally Low Interfacial Tension of Complex Coacervate Fluids
}

Kuo-Ying Huang, ${ }^{\dagger}{ }^{\circ}$ Hee Young Yoo, ${ }^{\ddagger}, \circ$ YongSeok Jho, ${ }^{\S} \|,{ }^{*}$ Songi Han, ${ }^{\dagger, *}$ and Dong Soo Hwang ${ }^{\ddagger},{ }^{*}$

${ }^{\dagger}$ Department of Chemistry and Biochemistry, University of California Santa Barbara, Santa Barbara, CA 93106 USA

${ }^{\ddagger}$ Division of Integrative Biosciences and Biotechnology, Pohang University of Science and Technology (POSTECH), Pohang 37673, Republic of Korea

${ }^{\S}$ Center for Soft and Living Matter, Institute for Basic Science (IBS), Ulsan 44919, Republic of Korea

"Asia-Pacific Center for Theoretical Physics, Pohang 37673, Republic of Korea

${ }^{\perp}$ School of Environmental Science and Engineering, Pohang University of Science and Technology (POSTECH), Pohang 37673, Republic of Korea

\section{Contents}

1. Supplementary Results

2. Supplementary Reference 


\section{Supplementary results}

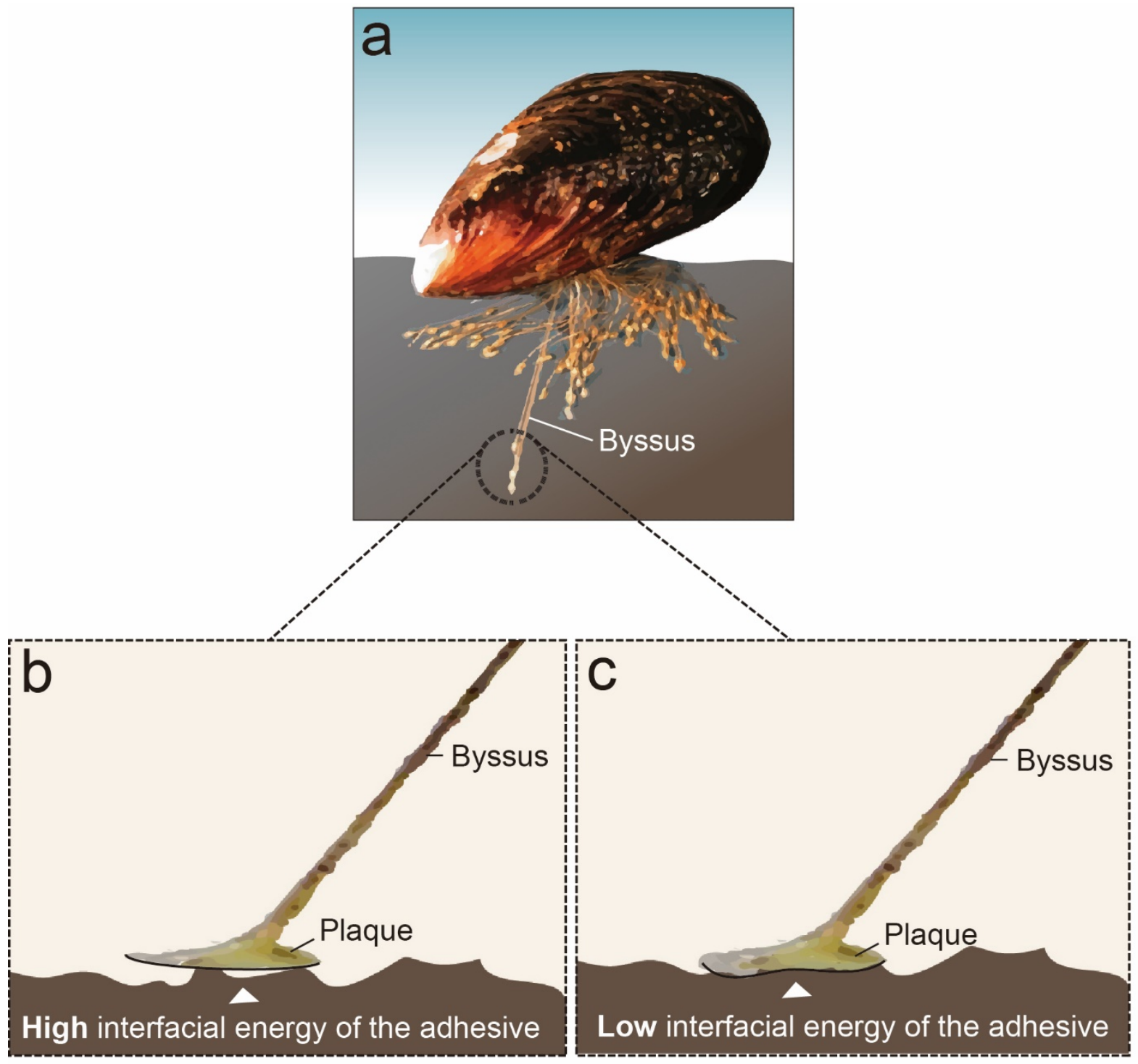

Figure S1. Schematic comparison of the mussel adhesion using byssal thread in case of high (left) and low (right) interfacial energy of the adhesive. 


\section{a}

mfp-1 sequence :

mfp-1 : M-(AKPSYPPTYK) 12

SLmfp-1 : M-(AKPSYPPTYK) ${ }_{11}$-AKPSTPPTKC

mfp-1<smiles>CC1(C)C=C(CSS(C)(=O)=O)C(C)(C)N1O</smiles><smiles>CC(C)(C)N[C@@H](CS)C(=O)C(C)(C)C</smiles><smiles>[Z][Z](C)(C)N[C@@H](CSSCC1=CC(C)(C)N([O])C1(C)C)C(=O)S(C)(C)C</smiles>

b

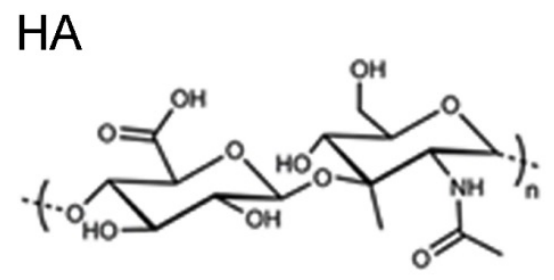

Figure S2. mfp1 sequence $\mathrm{M}(\mathrm{AKPSYPPTYK})_{12}$ and its mutant for spin-label. Cationic residues are indicated by red and the single cysteine for the spin label indicated in purple. Spin-labeled mfp-1 (SLmfp-1) is prepared by covalent functionalization of the single cysteine by the spin label MTSL. 


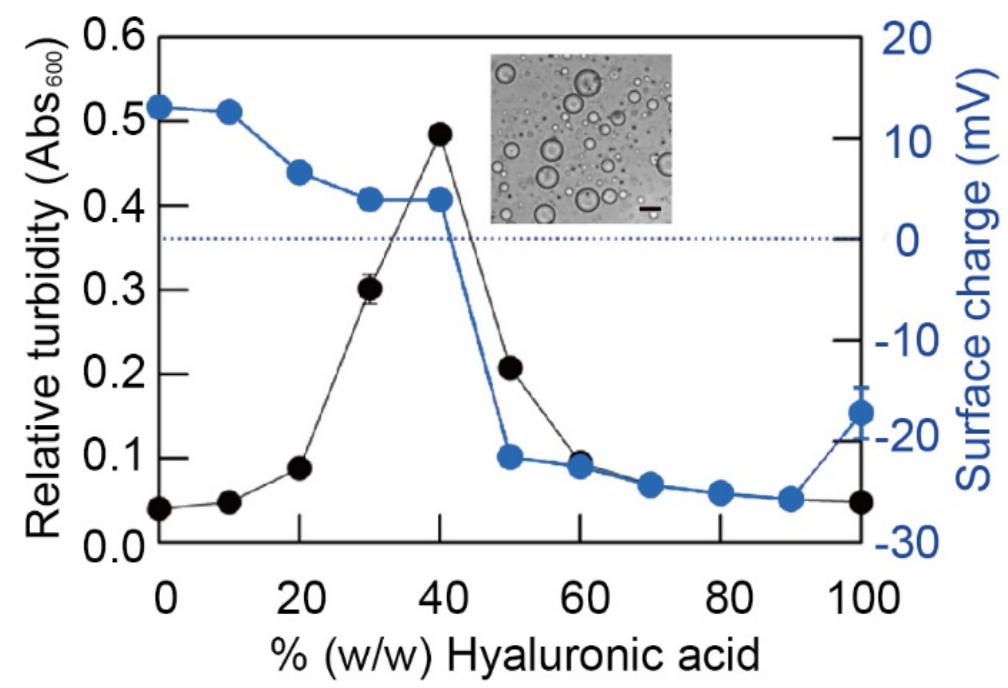

Figure S3. Coacervation of recombinant mussel protein (mfp-1) and hyaluronic acid mixtures. The yield of phase-separated coacervate is indicated by turbidity (black) and surface charge of coacervates as indicated by the zeta potential (blue). Each point represents the average of duplicate measurements. (Inset) Light microscopy image of micro-droplets of HA and fp- 1 coacervate. Scale bar is $25 \mu \mathrm{m}$. 

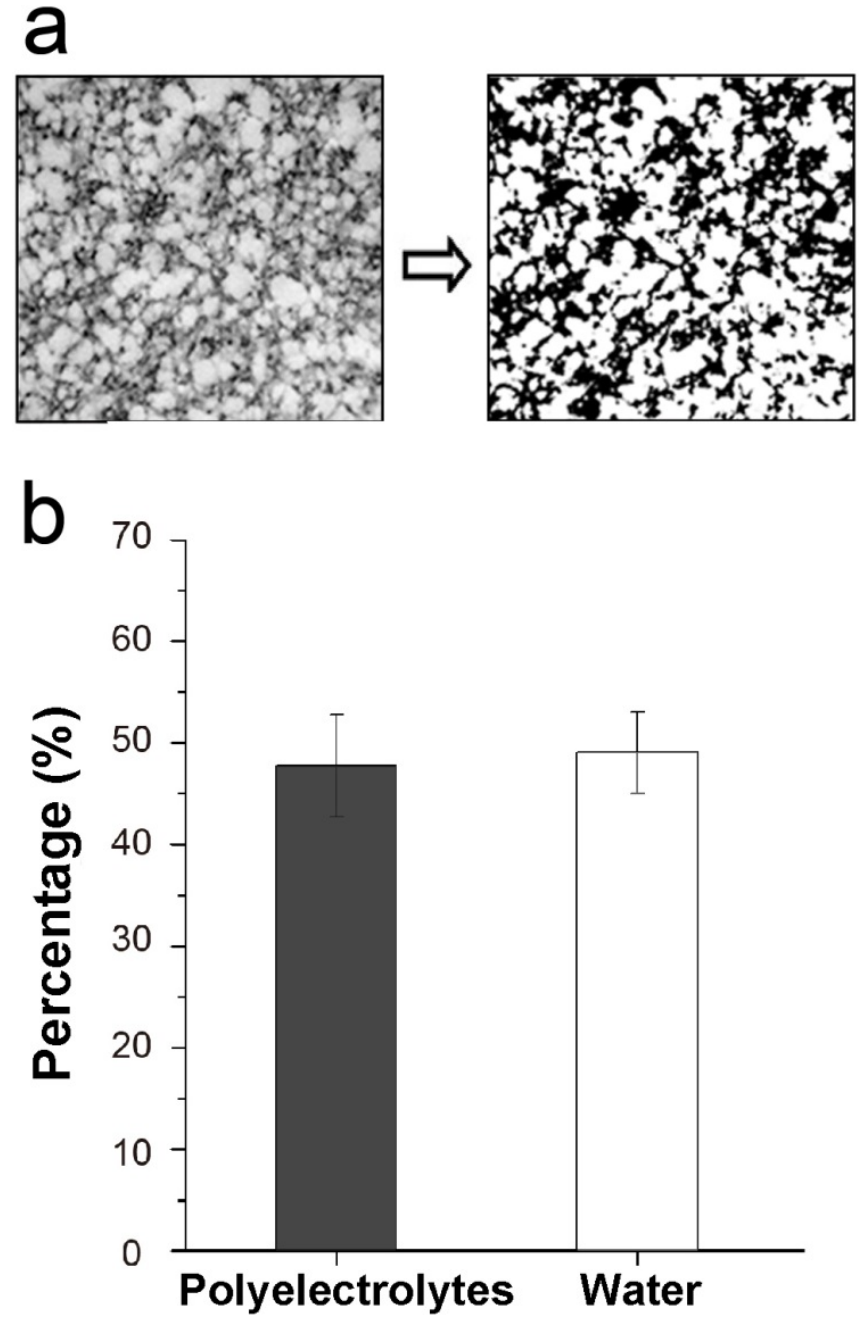

Figure S4. Calculation of the ratio of the polylelectrolytes and water from cryo-TEM images. 
Table S1. ODNP results and calibrated coupling constants and diffusion coefficients of 4hydroxy TEMPO in dilute and dense phase coacervates

\begin{tabular}{|c|c|c|c|c|c|c|c|}
\hline $\begin{array}{l}\text { Spin } \\
\text { probe }\end{array}$ & $\begin{array}{l}\text { 4-hydroxy } \\
\text { TEMPO } \\
\text { concentration }\end{array}$ & $\begin{array}{l}\text { Saturation } \\
\text { Factor, } \\
\mathrm{S}_{\max }{ }^{\mathrm{a}}\end{array}$ & $\begin{array}{l}\mathrm{K}_{\sigma} \mathrm{S}_{\max } \\
(1 / \mathrm{M} \cdot \mathrm{s})\end{array}$ & $\begin{array}{l}\mathrm{K}_{\rho} \\
(1 / \mathrm{M} \cdot \mathrm{s})\end{array}$ & $\xi \mathrm{S}_{\max }$ & $\begin{array}{l}\text { Coupling } \\
\text { constant, } \\
\xi\end{array}$ & $\begin{array}{l}\text { Diffusion } \\
\text { coefficient } \\
\left(\times 10^{9} \mathrm{~m}^{2} / \mathrm{s}\right)\end{array}$ \\
\hline $\begin{array}{l}\text { In } \\
\text { dense } \\
\text { phase }\end{array}$ & $20 \mathrm{mM}$ & 0.87 & 91 & 435 & 0.21 & 0.242 & 1.4 \\
\hline $\begin{array}{l}\text { In } \\
\text { dilute } \\
\text { phase }\end{array}$ & $20 \mathrm{mM}$ & 0.87 & 75 & 340 & 0.22 & 0.254 & 1.5 \\
\hline
\end{tabular}

a: Saturation facors of free nitroxide radicals are spin concentration dependent. For $20 \mathrm{mM}$ 4hydroxy TEMPO, saturation factor is about 0.87 based on the equation presented by Bennati et. al. ${ }^{9}$

$$
S_{\max }=1-\frac{2}{3+3 b}, \quad b^{\prime \prime}=C \times 198.7 \mathrm{M}^{-1}
$$




\section{Reference}

(1). Bennati, M.; Luchinat, C.; Parigi, G.; Turke, M.-T. Water 1H relaxation dispersion analysis on a nitroxide radical provides information on the maximal signal enhancement in Overhauser dynamic nuclear polarization experiments. Phys. Chem. Chem. Phys. 2010, 12, 5902-5910. 